\title{
DeVeloping Principles of BUiLding THE Simulator For ENERGY WORKER AND TECHNOLOGY FOR COAL MINE Electrical SERVICE StafF Training
}

\author{
Parshina Galina, Feshin Boris \& Breido Josif
}
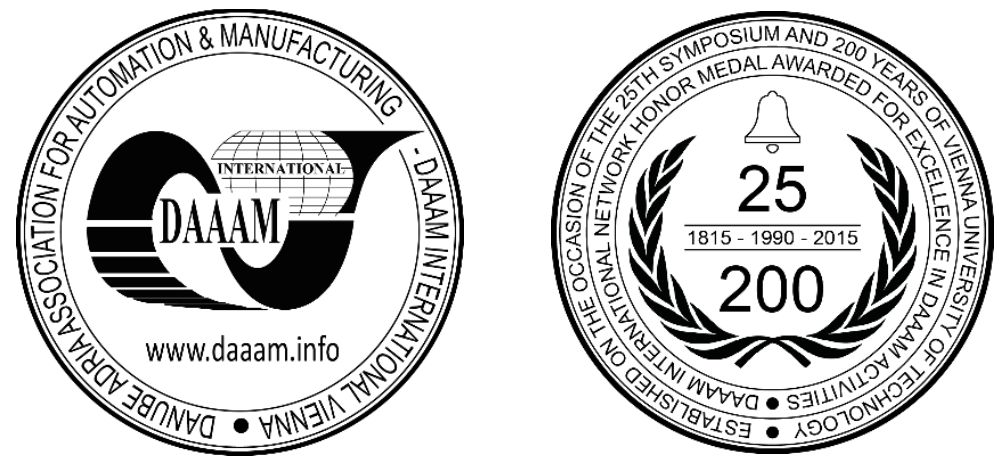

This Publication has to be referred as: Parshina, G[alina]; Feshin, B[oris] \& Breido, J[osif] (2016). Developing Principles of Building the Simulator for Energy Worker and Technology for Coal Mine Electrical Service Staff Training, Proceedings of the 27th DAAAM International Symposium, pp.0595-0599, B. Katalinic (Ed.), Published by DAAAM International, ISBN 978-3-902734-08-2, ISSN 1726-9679, Vienna, Austria DOI: $10.2507 / 27$ th.daaam.proceedings.087

\begin{abstract}
The article discusses the specifics of developing a virtual computer simulator of energy worker and a technology for training personnel of electrical services of coal mines. The paper describes the scope and main principles of simulator systems. The proposed energy worker's simulator model is described as a dual system: "Knowledge Base subsystem + Knowledge Control subsystem". In the work, we propose to build a training center for energy workers on the basis of the simulator, automated calculation of diagrams for calculating production units' power supply, as well as instruction and knowledge assessment system. The article presents a functional diagram of a training center equipped with a virtual simulator and considers two approaches in distributing software between the server and training center clients analyzing the advantages of each approach. Moreover, the work describes the technology for training coal mine electrical services employees and proposes an algorithm for using the simulator in training and controlling knowledge of this staff focusing on the advantages of using the simulator.
\end{abstract}

Keywords: simulator; power supply system; coal mine; electrical service, automated.

\section{Introduction}

Due to IT development, simulators for acquiring professional skills by technological production staff had become widespread over the last few years, especially for production presenting threats to life and health. Virtual simulators are often used as simulators of abnormal situations and emergency. This is justified technically and financially during the operation of technological facilities in highly explosive and fire hazardous industries [1-3].

One of those industries that are dangerous to life and health is production units of coal mines [4, 5]. Quality work which is achieved by many factors, among which not the last place is occupied by such as providing of reliability, security, functionality, necessary and acceptable performance of the mining electromechanical equipment. Calculations of power supply systems of electrical facilities of a mine, tunneling areas and producing units are carried out by electrical service personnel and approved by a chief power engineer of a coal mine. The consequences of errors in such calculations associated with insufficient qualification of the personnel can be disastrous. The works [6,7] proved that the efficiency 
and reliability of mining electromechanical equipment and safety of relevant staff greatly depend on the quality of calculation and design of diagrams of production units' power supply.

The article describes the principles of building the simulator and technology for training coal mine electrical services employees to obtain practical skills of calculation, design and operation of power supply systems of production units of coal mines.

\section{Basic principles of building the simulator}

The proposed simulator model is based on the three principles:

1. The basis for the creating the simulator is a simulator model. In turn, a simulator model is built on the basis of a simulated model of the production process (SM PP). SM PP virtually displays the operation of a technological object in predetermined industrial conditions (including normal, emergency, catastrophic). The present work considers an automated system for calculating power supply of coal mine production unit (ASCPS) as a simulator model [6]. Many industrial conditions are displayed as a multitude of ASCPS conditions which ensures the identity of real production process and simulator models for specific analyzed conditions of a production unit and available electromechanical equipment.

2. Virtual operator interface of a simulator reproduces real production networks of a technological object for specific industrial conditions. When calculating and designing power supply of production units, sequence of automated calculation and choice of instruments is taken similar to the algorithm used in manual calculation and construction (design) of power supply diagrams by a chief power engineers of coal mine.

3. The simulator is a tool of transferring knowledge from the experienced professional to apprentice. Experienced professionals may be the expert group with extensive experience in developing power supply diagrams [8]. Knowledge of the expert group are used to generate lists and content of training tasks, standard problem solutions both for the learning system and knowledge control system of the simulator for a variety of work situations and at different stages of training: beginner, intermediate and final assessment [6].

\section{Model of a training center with the simulator}

The model and computer simulator of energy worker itself is built on the basis of the subsystem of calculating power supply of workstation of electrical service employee. This ensures the identity of the simulator and the workplace of electrical worker.

The simulator, automated system for calculating power supply of coal mine production unit and training and knowledge control system (TKCS) may be on the same electronic computing machine at the training center which is organized in the form of training places in a format "client-server" connected in a common local/global cloud network.

The main link of the training center is server. The server has the database and simulator-related software installed. Software distribution between server and clients depends on the adopted approach:

1. at thick client technology, minimum software is installed on the server, and the simulator itself and all its accompanying software is located on workstations;

2. at thin client technology, switching software functions in the client, while the simulator and accompanying software is located on the server.

Choice of the first or second approach is determined as a function of bandwidth. At low bandwidth capacity, thick client approach is used with minimizing network traffic. At high bandwidth capacity, thin client approach is used which allows to unload a user's computer and simplify software administration process. Figure 1 is a functional diagram of a training center with a virtual simulator of energy worker.

\section{Methods of training}

Let us present simulator of energy worker as a dual system "Knowledge Base subsystem + Knowledge Control subsystem" [9, 10]. Apparent effectiveness of the simulator will be achieved if certain standard tested and/or trained employees score the necessary amount of points that characterize positive solution of control tasks over a fixed time and for the entire multitude of industrial mine conditions [8,11-14]. Suppose that experts who develop training tasks and tests can heuristically evaluate the quality of the simulator work. Evaluation of employee's competence is conducted at all stages of training and control: beginner, intermediate, and final. 


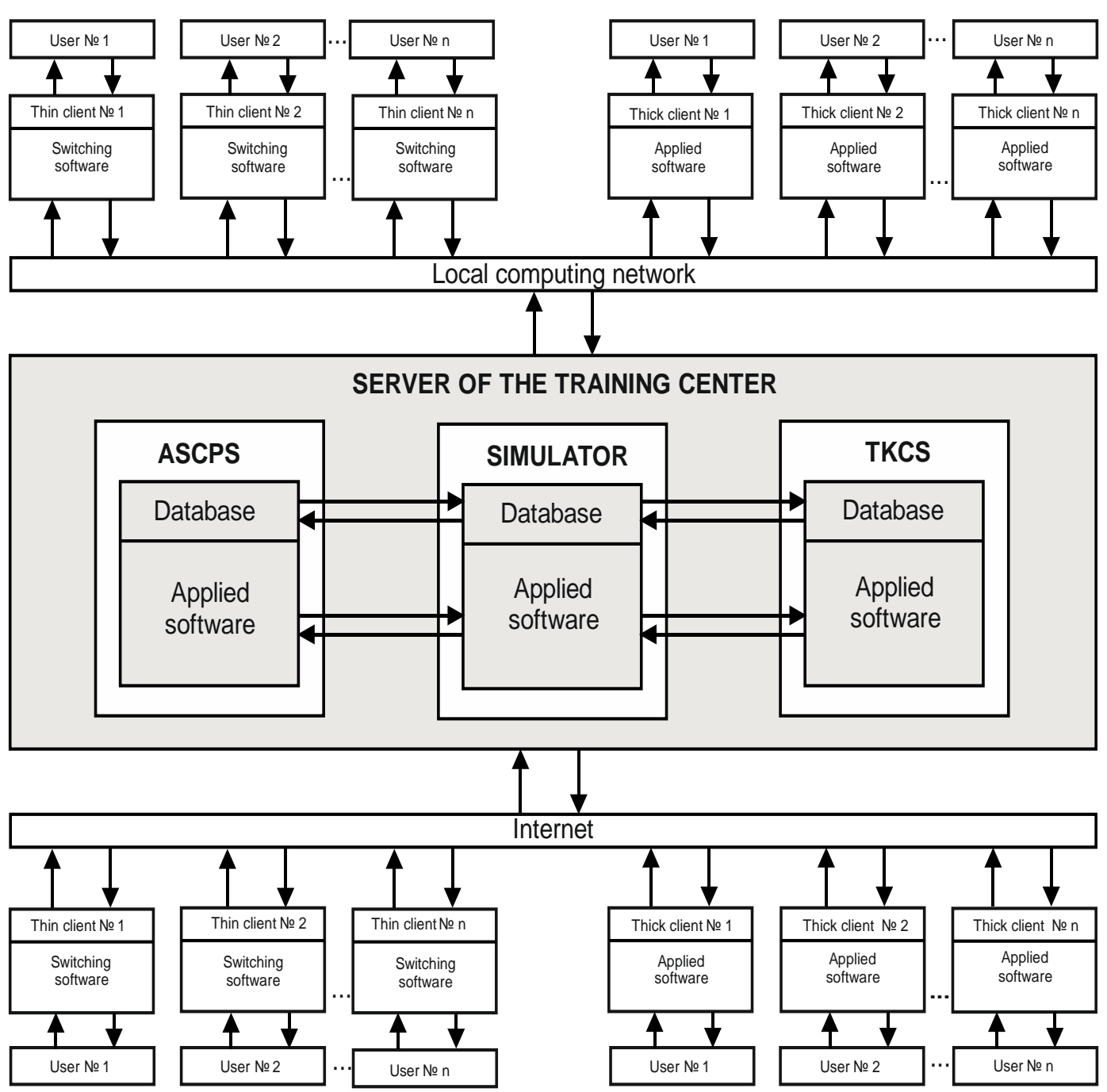

Fig.1. Functional diagram of a training centre with a virtual simulator of energy worker

The process of training and knowledge control by simulator of energy worker is a phased implementation of strict algorithmic operations by a person in split and real-time $[6,7,11-14]$ format, including:

1. for evaluating initial knowledge of the tested: generation of the initial data; calculation and design of production unit power supply diagram by the employee through the tools of automated workstation;

2. assessment of the calculation results according to step 1. In case of a negative result, go to step 3 . In case of a positive result, go to step 5;

3. training through the simulator tools;

4. assessment of learning outcomes. In case of a negative result, go to step 3. In case of a positive result, go to step 5;

5. training in a variety of control tasks;

6. assessment of training by step 5. In the case of a negative result, go to step 3. In case of a positive result, go to step 7;

7. multiple training of the employee;

8. assessment of learning outcomes by the technology of multiple training according to step 7. In case of a positive result, go to step 10. In case of negative result, go to step 9;

9. administrative and psychological assessment of knowledge and capabilities of the employee, recommendations for retraining and/or change of the working place of the employee.

10. issuance of a certificate and work admission of the mine electrical service employee.

In the training and knowledge control system, the simulator is used at all stages, learning, training and knowledge control. 


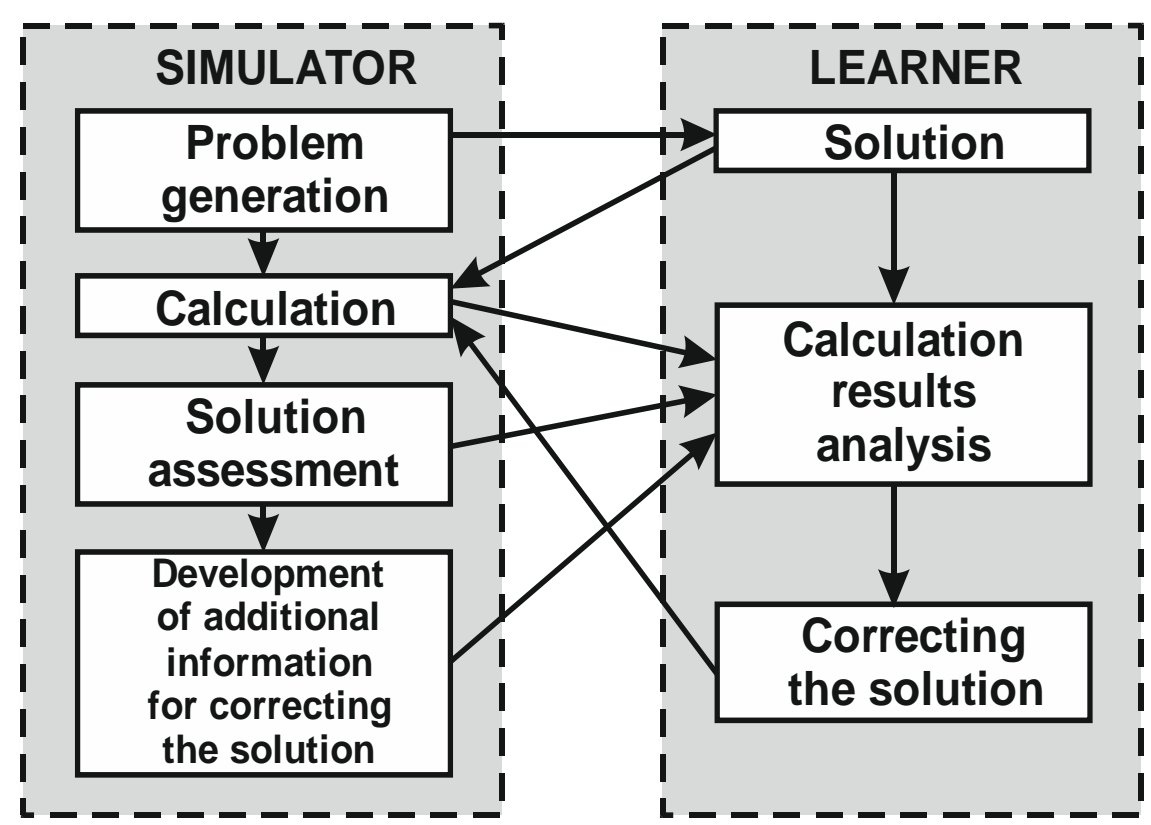

Fig. 2. Diagram of operational scenario of energy worker's simulator

In learning mode, the simulator has a function that allows a learner to compare his actions with the right ones while the training tasks are supplemented with explanation of standard solutions and provide links to sections of the training system on specific issues of decision-making. The algorithm of the simulator work in the learning mode includes the following steps:

1. generation of the initial data of the problem;

2. solution of the problem;

3. comparison of the problem solution with standard answers and assessment of the solution by a 100-point scale;

4. in the case of non-complete compliance of the problem solution results with standard answers, a set of additional data is offered; it is available to form a new control task and then go to step 2. Upon acceptable compliance of the problem solution with the standard answers, transition to step 5 is necessary;

5. end of the simulator work.

\section{Conclusion}

The offered simulator model built on the basis of the basic principles of creating such systems. Simulator model is described as a dual system: "Knowledge Base subsystem + Knowledge Control subsystem". Functional diagram of a training center is based on two main approaches in distributing software between the server and training center. Technology training and control of knowledge includes the algorithm to use the simulator at all stages of preparation and control.

Creation and implementation of a system consisting of subsystems of training and knowledge control, simulator, and automated calculation and design of power supply systems of coal mine production units provides for the following split and real-time opportunities:

- getting an estimate, a rating of coal mine electrical services personnel for the admission to operation of electrical equipment;

- obtaining the predictive assessment of a failure-free level of electrotechnical facilities of a mine production unit;

- increasing the rating of electrical services personnel by means of targeted training and knowledge control;

- automating the calculation of power supply of production units of coal mines;

- reducing the complexity of calculating the mine power supply diagrams;

- improving the calculation efficiency and quality by automating basic procedures;

- reducing the probability of errors during the calculation of power supply diagrams;

- reducing the risk contributed by individuals when making design decisions concerning power supply systems of coal mines' production units. 


\section{References}

[1] Victor Hreniuc, Ghiorghe Batrinca, A Pleading for Ship Manned Models as a "Physical" Simulator in the Ship Handling Training Process. Procedia Engineering, Volume 69, 2014, pp. 1410-1419, ISSN 1877-7058 doi:10.1016/j.proeng.2014.03.136, Editor B. Katalinic, Published by DAAAM International, Vienna, Austria, 2014.

[2] G.Ya. Pyatibratov, O.A. Kravchenko, A.M. Kivo, Design Principles and Implementation of Advanced Simulators for Training Astronauts to Work in Zero or Low Gravity Conditions. Procedia Engineering, Volume 150, 2016 , pp. 1410-1414, ISSN 1877-7058, http://dx.doi.org/10.1016/j.proeng.2016.07.337, Editor B. Katalinic, Published by DAAAM International, Vienna, Austria, 2016.

[3] Przemysław Mądrzycki, Dariusz Karczmarz, Piotr Golański, Usage of Diagnostic Simulator for Ground Engineering Crew Training. Procedia Computer Science, Volume 22, 2013, pp. 395-400, ISSN 1877-0509, doi:10.1016/j.procs.2013.09.117.

[4] Rules for industrial safety in hazardous industrial facilities of coal mines. Approved by order of the Minister for Investment and Development of the Republic of Kazakhstan of December 30, 2014. No. 351. - 225 pp.

[5] Safety code for operation of consumer electric installations. Approved by the RK Government Resolution of 24 October, 2012. No. 1353. Astana. - 97 pp.

[6] Parshina G.I. \& Feshin B.N., The automated system of calculation of power supply systems of stope face of coal mines. Proceedings of the International Scientific and Practical Conference "Informatization of Engineering Education", ISBN 978-5-383-00939-0, Moscow, Publishing House MEI, April 12-13, 2016. pp. 390-393.

[7] Parshina G.I. \& Feshin B.N., Developing the Structure of a Database for Automated Calculation of Coal Mines Producing Units' Power Supply. University Proceedings, ISSN 1609-1825, Karaganda, KSTU publisher, Issue No. 4(61), 2015, pp. 76-81.

[8] Feshin B., Parshin G., System of Providing of Effective Using of Electrotechnical Complexes of Mining Department of Mines. 22nd World Mining Congress \& EXPO 11-16 September Istanbul-2011, volume-III, 2011. ISBN: 978605-01-0146-1 (Tk.), 978-605-01-0149-2 (III. Vol.), pp. 441-448. Editor Dr. Şinasi Eskikaya, Published by Aydoğdu Ofset, Ankara-Turkey, İSTANBUL, 2011

[9] Ulrika Hurt, Tauno Otto, Kati Kõrbe Kaare, Ott Koppel, New Approach to Knowledge Transfer Environment Development. Procedia Engineering Volume 69, 2014, pp. 273-281, ISSN 1877-7058 doi:10.1016/j.proeng.2014.02.232, Editor B. Katalinic, Published by DAAAM International, Vienna, Austria, 2014.

[10] Rakic Kresimir, Bandic Glavas Marijana, Majstorovic Vlado, Development of the Intelligent System for the Use of University Information System. Procedia Engineering, Volume 69, 2014, pp. 402-409, ISSN 1877-7058, doi:10.1016/j.proeng.2014.03.005, Editor B. Katalinic, Published by DAAAM International, Vienna, Austria, 2014.

[11] Parshina G.I. \& Feshin B.N. Expert Knowledge Quality Evaluation Systems of the Mining Electrotechnical Units' Personnel. International workshop "System Analysis, Management and Information Processing" (27th - 30th September, 2010) — Rostov-on-Don: DGTU publisher, 2010.

[12] Parshina G.I., Automated Systems of Production Units' Power Supply Calculation as a Basis of Coal Mines' Operation Safety. University Proceedings, ISSN 1609-1825, Karaganda, KSTU publisher, Issue No. 3, 2010 , pp. 89-93.

[13] G.I. Parshina, High Performance System for the Operation of the Electrotecnical Units of the Coal Mines' Production Departments. Automation and Informatics, ISSN 1560-7305, Karaganda, KSTU publisher, Issue No. 12 (26- 27), 2010, pp. 32-35.

[14] Parshina G.I. Development of Automated System of Training and Control Knowledge Staff Electrical Services. Proceedings of the International Scientific and Practical Conference "Informatization of Engineering Education", ISBN 978-5-7046-1535-4, Moscow, Publishing House MEI, April 15-16, 2014. pp. 451-454. 